\title{
Pick of the year 2014
}

Published online: 10 March 2015

(C) The International CCN Society 2015

Upon my invitation to participate in this Special Series of Bits and Bytes, some members of the JCCS edtorial board have accepted to comment on a 2014 paper that they enjoyed reading very much.

My « instructions to authors » were quite simple and permissive ....

« the length of your comment can be from a few lines up to a few pages....Your choice of topic : Any article that you particularly enjoyed reading this year $»$.
I am sincerely grateful to our colleagues who responded positively and accepted to " play the game » in spite of the short notice given, very busy schedules and other deadlines.

I would like to emphasize that all readers are kindly invited to feed the Bits and Bytes section all year long !

February 10, 2015

Bernard Perbal

Editor in Chief JCCS 